\title{
The gap in life expectancy from preventable physical illness in psychiatric patients in Western Australia: retrospective analysis of population based registers
}

\author{
(a) (1) $\Theta$ OPEN ACCESS
}

\author{
David Lawrence research professor ${ }^{1}$, Kirsten J Hancock senior analyst ${ }^{1}$, Stephen Kisely professor ${ }^{23}$
}

${ }^{1}$ Telethon Institute for Child Health Research, Centre for Child Health Research, The University of Western Australia, PO Box 855 West Perth WA 6872 Australia; ${ }^{2}$ School of Medicine, The University of Queensland, Brisbane, Australia; ${ }^{3}$ Griffith Institute for Health and Medical Research, Griffith University, Brisbane, Australia

\begin{abstract}
Objective To examine the mortality experience of psychiatric patients in Western Australia compared with the general population.

Design Population based study.

Setting Western Australia, 1985-2005.

Participants Psychiatric patients (292 585) registered with mental health services in Western Australia.

Main outcome measures Trends in life expectancy for psychiatric patients compared with the Western Australian population and causes of excess mortality, including physical health conditions and unnatural causes of death.

Results When using active prevalence of disorder (contact with services in previous five years), the life expectancy gap increased from 13.5 to 15.9 years for males and from 10.4 to 12.0 years for females between 1985 and 2005 . Additionally, $77.7 \%$ of excess deaths were attributed to physical health conditions, including cardiovascular disease $(29.9 \%)$ and cancer $(13.5 \%)$. Suicide was the cause of $13.9 \%$ of excess deaths.

Conclusions Despite knowledge about excess mortality in people with mental illness, the gap in their life expectancy compared with the general population has widened since 1985. With most excess deaths being due to physical health conditions, public efforts should be directed towards improving physical health to reduce mortality in people with mental illness, in addition to ongoing efforts to prevent suicide.
\end{abstract}

\section{Introduction}

The excess mortality associated with mental illness has been extensively documented. ${ }^{12}$ Much of the attention has focused on the increased risks of suicide, ${ }^{3}$ even though most of the risk of excess mortality is due to physical health illnesses, such as cardiovascular disease, respiratory disease, and cancer. ${ }^{4-6}$ Excess mortality in people with mental illness is generally reported in terms of standardised mortality rates and mortality rate ratios, but other measures can be used, such as potential years of life lost, ${ }^{7}$ average age at death, and life expectancy. As mortality rates in people with mental illness vary with time since onset of the disorder and age of onset, one disadvantage of using mortality rate ratios is that the composition of the cohort studied and the follow-up time can affect the outcome. ${ }^{8}$ Life expectancy can be a useful alternative. Because it is calculated by cumulating across all ages, life expectancy can reflect changes in mortality rates across ages. It also expresses the results in a metric that is intuitively easy to understand. Life expectancy is most commonly used to describe the mortality rates of geographically defined populations, but the technique has also been used for populations defined by demographic characteristics or diagnosis.

Of the few studies of life expectancy in people with mental illness, some have been restricted to inpatients and others to people with severe mental illnesses, such as schizophrenia and bipolar disorder. One study reported a reduction in life expectancy of 14 years for males and six years for females treated by the Massachusetts Department of Mental Health. ${ }^{9}$ Another study reported a reduced life expectancy in nine diagnostic groups from patients in contact with Swedish psychiatric clinics. ${ }^{10}$ More recently several reports on life expectancy in Nordic countries have been published, with the life expectancy of psychiatric patients reduced by 20 years in males and by 15 years in females compared with the general population. ${ }^{11}{ }^{12}$ A group of patients with severe mental illness from a secondary care case register in London were found to have a reduced life expectancy of between eight and 15 years for males and 10 and 18 years for females. ${ }^{13}$ These were generally cross sectional studies and little is known about whether these benefits have extended to those with mental illness 
and whether the life expectancy gap between people with mental illness and the general population has changed over time. Although some research has shown that the mortality rate for people with schizophrenia has increased in the past three decades, ${ }^{14}{ }^{15}$ only one study has examined this relation longitudinally using measures of life expectancy. ${ }^{12}$ This study showed only a modest narrowing of the life expectancy gap in Denmark, Finland, and Sweden, countries with arguably some of the best and most equitably distributed healthcare in the world. ${ }^{16}$

We examined the mortality experience of psychiatric patients in Western Australia compared with the general population. Using a population based register of contacts with mental health services (including inpatient, outpatient, and community care based clients), we calculated trends in life expectancy among psychiatric patients compared with the total Western Australian population. We also examined causes of excess mortality in psychiatric patients and calculated the contribution of major causes of death to excess mortality rates, including cancer, heart disease, respiratory disease, and unnatural causes of death.

\section{Methods}

We extracted the data for this study from population wide databases covering the state of Western Australia. This state is well suited to population based record linkage studies because of its relative geographical isolation. The population of Western Australia increased from 1.4 million in 1985 to 2.02 million in 2005. ${ }^{17}$

\section{Data sources}

\section{Mental health information system}

The mental health information system records contacts with mental health services in Western Australia. This database started as a register of patients in psychiatric hospitals in 1966, and its scope was expanded in the 1970s to include all other hospitals and community mental health services. Since 1980 it has covered all inpatient admissions to private or public hospitals in Western Australia where a diagnosis of mental disorder or self harm has been made or where contact has occurred with a specialist psychiatric service, along with all outpatient and community based contacts with public mental health clinics. ${ }^{5}$

The system records basic personal data about each patient, including date of birth and sex, and service use data including dates of admission and discharge, periods of leave, and primary diagnoses. The register is comprehensive in its coverage of contacts with these services in Western Australia ${ }^{18}$; a validation study of selected diagnoses in the register found a high sensitivity and specificity for schizophrenia and affective psychosis diagnoses. ${ }^{19}$

\section{Death registrations}

All deaths occurring in Western Australia are registered by the registrar general. Cause of death is coded by the Australian Bureau of Statistics based on information provided on the death certificate or by the coroner's determination of cause of death. Cause of death was coded using ICD-9 (international classification of diseases, ninth revision ${ }^{20}$ until 1998 and then ICD-10 ${ }^{21}$ from 1 January 1999.

\section{Record linkage}

The mental health information system and death registrations in Western Australia have been linked using probabilistic record linkage techniques as part of the Western Australian data linkage system..$^{20}$ Because there are no unique identification numbers common to both datasets, probabilistic matching is undertaken using name, residential address, date of birth, and sex as the principal matching fields. Probabilistic linkage allows for the possibility of errors or changes in the identifying information used for matching. Once record linkage has been undertaken, deidentified linked files are provided to researchers and all analysis is undertaken on anonymised data. The proportion of invalid and missed links using this method has been estimated at $0.11 \% .^{22}$

\section{Measures \\ Principal psychiatric diagnosis}

The mental health information system identifies mental disorders using codes: ICD-8 (international classification of diseases, eighth revision), ${ }^{23}$ ICD-9-CM (Australian version of the international classification of diseases, ninth revision, clinical modification) ${ }^{24}$ or ICD-10-AM (international statistical classification of diseases and related health problems, 10th revision, Australian modification). ${ }^{25}$ ICD-9 was introduced in 1979 , followed by ICD-10-AM in 2000. We identified hospital admissions and contacts with mental health clinics for mental disorders if an ICD-8 or ICD-9 chapter 5 diagnosis or ICD-10 chapter F diagnosis was made. For the purposes of this study, we excluded patients with all types of dementia, because of the typically older age of onset of this disorder. On the mental health information system, a separate diagnosis is recorded for each episode of care. Where patients have had multiple episodes of care, more than one principal diagnosis may have been assigned over the course of those admissions. We assigned a principal psychiatric diagnosis by using the most recent diagnosis subject to a hierarchy that gave preference to an earlier diagnosis if the later one was less informative or likely to refer to a comorbidity. Full details of this method are described elsewhere. ${ }^{5}$ Briefly, if the last episode of care recorded a diagnosis of alcohol dependence but a previous episode recorded schizophrenia, then we would assign a diagnosis of schizophrenia. This method was designed to give precedence to more severe disorders and to allow for certain conditions, such as substance dependence, to be considered as a potential comorbidity. We then grouped diagnoses into eight categories: alcohol or drug disorders, schizophrenia, affective psychoses, other psychoses, neurotic disorders, stress or adjustment reaction, depressive disorders, and other mental disorders. At this level, more than $70 \%$ of people on the mental health information system had only one diagnosis recorded.

\section{Major causes of death}

We coded deaths according to both ICD-9 and ICD-10. To ensure maximum comparability over time, we identified major causes of death using comparable ICD-9 and ICD-10 codes as recommended by the US Centers for Disease Control. ${ }^{26}$ The supplementary table shows the ICD-9 and ICD-10 codes used to define each major cause of death. Cause of death is coded by the Australian Bureau of Statistics. Where there is more than one contributing cause of death, the disease or injury that initiated the train of morbid events directly leading to death is coded as the main cause of death. ${ }^{27}$ Accidental and violent deaths are classified according to the external cause of death. Suicide is initially determined by coronial verdict. Where the coroner is unable to make a finding as to intent because of the high legislative standard for determining this or because of cultural or religious sensitivities, the Australian Bureau of Statistics undertakes further investigation of the death using information 
on the national coronial information system and codes the death as a suicide where there is evidence of intent. Deaths where intent cannot be established are coded as other accident or injury. ${ }^{28}$

\section{Statistical analysis}

\section{Life expectancy}

We calculated life expectancy at birth using the abridged life tables method as previously described. ${ }^{29}$ The concept of life expectancy in any given year is based on what would be expected to happen to a hypothetical cohort if each individual was subjected throughout his or her life to the same age-sex specific mortality rates that were observed during that year. As such life expectancy does not refer to any specific individual, as mortality rates change over time.

The abridged life tables method uses mortality rates in a specific cohort within five year age groups to estimate life expectancy. This method is used by the UK Office for National Statistics to estimate life expectancy for regional areas owing to its suitability for smaller cohorts. ${ }^{30} 31$ To smooth out variability from smaller cohort sizes, we used deaths within five year periods rather than single year figures to calculate age specific mortality rates. For example, the life expectancy estimate for 1985 was based on deaths occurring in 1983-87, the estimate for 1986 was based on deaths occurring in 1984-88, and so on. As a result, although data were available from 1983 to 2007, the results presented in this study cover the period 1985 to 2005 . Because of the small numbers of psychiatric patients under the age of 15 years, we assumed that the mortality rate in psychiatric patients before age 15 was equal to the mortality rate in the general population for that age group.

Mortality rates within five year age groups formed the basis on which we constructed abridged life tables. We calculate these mortality rates by dividing the number of deaths within the cohort within the appropriate age group and year span, by the total number of person years contributed by people in the cohort by age group and year range. For the eight disorder groups we calculated mortality rates and life expectancy at birth separately for males and females.

We compared life expectancy in the cohort of psychiatric patients with life expectancy at birth for the total Western Australia population, which is published by the Australian Bureau of Statistics. ${ }^{32}$ The bureau uses a moving three year average for calculating the mortality rates that underpin the population wide life tables.

As the mental health information system only started in 1966, and as life expectancy in the general population has increased and the nature of mental health service delivery has expanded with greater emphasis on community based care, the tendency has been for the proportion of the population with a history of contact with mental health services to increase over time. To tackle this problem we defined a cohort of "active" cases on any given date as people with ongoing contact with mental health services or who had contact with services in the five years preceding that date. This gave a more constant basis for observing changes in life expectancy over time. Therefore our primary cohort definition was based on people who had contact with mental health services in the past five years for each reference year. Within each five year window, we calculated person years at risk from date of first contact with mental health services if this date was within the past five years, or from the start of the five year period if first contact with mental health services was before that date.

\section{Excess mortality by cause of death}

We calculated the expected numbers of deaths in the cohort by major cause of death by using cause specific death rates by age group, sex, and time period for Western Australia obtained from the Australian Bureau of Statistics. ${ }^{33}$ We applied these rates to the total person years in the cohort of psychiatric patients. We then calculated excess mortality by cause as the difference between the observed number of deaths and the expected number of deaths.

All analysis was undertaken using SAS software. ${ }^{34}$

\section{Results}

Overall, 292585 people were in contact with mental health services in Western Australia between 1983 and 2007, of whom 47669 died in the same period. Table $1 \Downarrow$ shows the numbers of active cases and deaths in the first and last cohorts included in this study, those of 1983-87 and 2003-07. From the person years contributed by the cohort we calculated the age standardised prevalence of each mental health condition, as defined by contact with mental health services, and we estimated resident population counts for Western Australia from the Australian Bureau of Statistics. ${ }^{17}$ The active prevalence of disorder (proportion of the population in contact with mental health services in the preceding five years) increased over time for some disorders (fig $1 \Downarrow$ ), in particular affective psychoses and stress or adjustment reactions. The mental health information system is a population based case register of service contacts so these prevalence rates represent the active prevalence of having been treated for a psychiatric condition by mental health services in the previous five years. These increases in active prevalence may reflect changes in diagnostic practices or a greater focus on community based treatment options, which may result in larger proportions of the population coming into contact with services.

In the general population, life expectancy for males increased from 73.1 years in 1985 to 79.1 years in 2005 and for females from 79.3 years to 83.8 years (table $2 \Downarrow$ ). Among psychiatric patients, males and females with alcohol or drug disorders had the lowest life expectancy in 1985, and the gap in life expectancy exceeded 20 years at each time point. With the exception of females with stress or adjustment reactions, all disorders were associated with a significant gap in life expectancy throughout the study. For all mental disorders combined, the gap in life expectancy for males increased from 13.5 years in 1985 to 15.9 years in 2005 and for females from 10.4 years in 1985 to 12.0 years in 2005 .

In terms of individual diagnoses, the gap increased for both males and females with adjustment reaction, affective and other psychoses, and depression (figures $2 \Downarrow$ and $3 \Downarrow$ ). The largest increases in the life expectancy gap were seen for people with other psychoses (14.8 to 22.7 years for males and 14.1 to 22.6 years for females) and stress or adjustment reactions ( 7.3 to 13.2 years for males and -0.2 to 9.3 years for females, table 2). Overall, most excess deaths were due to physical health conditions, with cardiovascular disease (including stroke) the main cause of $26.2 \%$ of excess deaths in male psychiatric patients and $35.3 \%$ in female psychiatric patients, and cancer the main cause of $13.6 \%$ of excess deaths in males and $13.3 \%$ in females (table $3 \Downarrow$ ). Suicide was the cause of $16.6 \%$ of excess deaths in males and $10.1 \%$ in females. Other accidents and injuries accounted for another $8.1 \%$ of excess deaths in males and $7.0 \%$ in females. 
Although suicides represented a larger proportion of excess deaths for patients with affective psychoses $(46.4 \%$ of males and $27.4 \%$ of females), stress or adjustment reactions $(53.3 \%$ of males and $33.5 \%$ of females), and other mental disorders (33.4\% of males and $14.8 \%$ of females), physical conditions represent the majority of excess deaths for all psychiatric disorders. Cardiovascular disease was the main cause of a substantial proportion of excess deaths for all psychiatric conditions, but particularly for schizophrenia (31.8\% of males and $46.3 \%$ of females), other psychoses ( $32.5 \%$ of males and $40.6 \%$ of females), and neurotic disorders (38.3\% of males and $37.6 \%$ of females).

\section{Discussion}

Our study shows that the size of the gap in life expectancy for people with psychiatric disorders in Western Australia increased between 1985 and 2005, from 13.5 to 15.9 years for males and from 10.4 to 12.0 years for females. The majority of excess mortality was attributed to physical health conditions, such as cardiovascular disease, respiratory disease, and cancer. Although some studies have shown that the mortality rate has increased over time for people with schizophrenia, ${ }^{14}{ }^{15}$ only one study, based on data from Denmark, Finland, and Sweden, has examined changes in the life expectancy gap over time for a wider range of psychiatric conditions. ${ }^{12}$ In contrast with the Nordic study, which showed a slight reduction in the life expectancy gap, we found that the overall gap in life expectancy increased by 2.4 years for males and by 1.6 years for females between 1985 and 2005. Particularly large increases were found for both males and females with stress or adjustment reactions and with other psychoses. Given that the Nordic countries have some of the most comprehensive and equitable healthcare and social welfare in the world, our results may be more typical of the experience in other places. The increased gap is largely driven by increasing life expectancy in the general population rather than a reduction in life expectancy in psychiatric patients. While life expectancy in Western Australia is high among developed countries, the magnitude of increase in life expectancy between 1985 and 2005 in Western Australia is consistent with that seen in the United Kingdom, the United States, and many European countries. ${ }^{35}$ By examining gaps in life expectancy rather than mortality rates and by revealing that these gaps have increased over time, the results of this study are significant in that they show that outcomes for people with mental illness have worsened since the 1990s despite increasing knowledge about the impacts of such illness.

The widest gap in life expectancy was seen in people with alcohol and drug disorders, and this gap of more than 20 years was maintained throughout the period of study. As we assigned a principal psychiatric diagnosis for each patient in this study, the category for alcohol and drug disorders did not include patients with another psychiatric diagnosis and a comorbid substance use disorder but only those with a primary diagnosis of a substance use disorder. Substance misuse is a well established risk factor for cardiovascular disease and many cancers, so it is not surprising that the majority of excess mortality was attributable to heart disease, cancer, and liver disease.

Our findings suggest that the gap in life expectancy between psychiatric patients and the general population is worse than that for other disadvantaged groups. For instance, for lifelong smokers-a population that receives considerable public health attention and intervention-life expectancy is around 10 years less than non-lifelong smokers. ${ }^{36}$ The gap in life expectancy between Indigenous (Aboriginal and Torres Strait Islander) and non-indigenous Australians is approximately 12 years for males and 10 years for females. ${ }^{37}$ While inequalities in the health experiences of Indigenous Australians have justifiably attracted substantial public investment, ${ }^{38}$ little attention has focused on the mortality rates of people with mental illness in Australia, and there are few interventions designed to reduce the morbidity and mortality associated with common physical illnesses in people with mental illness.

\section{Possible causes of poor health outcomes in people with mental illness}

Apart from the increased risk of suicide with mental illness, most mental illnesses, although debilitating, are not direct causes of death. Traditionally, there has been a view that suicide and unintentional deaths were a major cause of excess mortality in people with mental illness, and the bulk of public efforts to reduce mortality in such people have been directed at suicide prevention. ${ }^{39}$ Our data show that almost $80 \%$ of excess deaths in people with mental illness are due to physical health conditions. Important advances have been made in reducing the rate of mortality from common physical health conditions in the general population, such as heart disease, respiratory disease, and some cancers. It seems as if people with mental illness have not benefitted to the same extent from these advances. ${ }^{12} 40$

Excess morbidity or mortality associated with mental illness is recognised as a complex multifactorial problem. ${ }^{40}{ }^{41}$ Higher rates of substance use have been well documented in people with mental illness, including tobacco, alcohol, and illegal drugs, ${ }^{42-44}$ as well as a higher prevalence of unhealthy lifestyles, including poorer diets and less exercise. ${ }^{45-47}$ The side effects of drugs, particularly the metabolic side effects of antipsychotics, have also received considerable attention. ${ }^{48}{ }^{49}$ Finally, inequalities in access to, and use of, healthcare are well documented. ${ }^{50}$ All of these factors may have contributed to the overall substantial and widening gap in life expectancy for people with mental illness in this study. Socioeconomic disadvantage is also more common in people with mental illness and is associated with health risk behaviours and reduced access to healthcare. ${ }^{51}$ However, studies that adjusted for socioeconomic status still found significantly worse morbidity and mortality for people with mental illness, ${ }^{28}$ showing that social deprivation and disadvantage are not the sole determinants of poor health outcomes in people with mental illness.

\section{Improving health outcomes for people with mental illness}

As multiple factors contribute to worse health outcomes in people with mental illness, a range of solutions is required both to deal with health risk factors at individual patient level and to ensure equitable access to healthcare. To tackle systemic barriers to healthcare provision, a range of solutions has been proposed, including integrated care models such as co-location of physical and mental health services or the use of case managers or other liaison staff to undertake a coordination role between services. ${ }^{50}{ }^{52}$ General practitioners also have an important part to play in managing the overall health needs of people with mental illness. Increasing access to screening and funding models that allow general practitioners to spend more time with patients with more complex problems may be advantageous..$^{53} 54$ In terms of health risk factors at individual patient level, the use of peer supporters or provision of healthcare skills training may help people with mental illness manage their health. ${ }^{556}$ Improvements in risk factor profiles, such as reducing smoking, improving diets, and increasing physical activity, have 
contributed to improvements in life expectancy in the general population. Adapting population health and health promotion approaches to more specifically target disadvantaged populations, including those with mental illness, could help extend these gains to population groups with multiple problems or disadvantages. ${ }^{50}$ Major improvements in health outcomes for people with mental illness are unlikely without system wide commitment to achieving equality in health service delivery and access. This may require health systems committing to targets for improvements in outcomes, regular monitoring of progress, equitable allocation of resources based on health need, and the integration of the needs of people with comorbid mental health problems into mainstream healthcare and public health initiatives. ${ }^{57}$ One example is Queensland's strategy to improve the physical health of people with severe mental illness (Activate: Mind and Body). ${ }^{58}$

One researcher ${ }^{16}$ argued that the continued gap in life expectancy shows the poor value that society places on people with mental illness and that the lost years of life are viewed by society with "cynical disregard." Psychiatric patients in this study represented over $5 \%$ of the Western Australia population, including a large proportion of people who had only short contacts with services. ${ }^{59}$ Although the pervasive stigma associated with mental illness may lead some to believe otherwise, many adults in this group have families, are employed, and would be expected to be making a contribution to their families and communities. The opportunity for them to do so is being foreshortened by premature mortality. ${ }^{60}$ Addressing both the physical and mental health of people with mental illness would allow such people to participate more fully in society, including through increased employment opportunities and reduced absenteeism.

\section{Limitations of this study}

Limitations of this study include the reliance on administrative data of contacts with services. Not all people with mental illness have contact with services, and these data have to be considered representative of the population of people in contact with services, not all people with mental illness. For instance, the register does not cover people with undiagnosed and untreated disorders and those who are only treated by general practitioners or private psychiatrists and psychologists. People with disorders who are not in contact with services may have different mortality, and possibly worse, outcomes than those in contact with services. Changes in life expectancy over time could be influenced by changes in service delivery and diagnostic practices. As the overall prevalence of contact with mental health services has increased over time, however, and if it is assumed that the most severe cases at any point in time are most likely to receive treatment, the increasing prevalence would be expected to reduce the observed gap in life expectancy, not increase it, assuming that the most severe cases have the worst mortality outcomes. Because the mental health information system started at a fixed time, and to avoid change over time being biased by the accumulation of more and more cases, we used an active case definition - that is, people who had ongoing contact with services or contact within the five years before each reference date. Changes in cause of death coding over time could have affected the estimates of excess death by cause. For instance, HIV has been coded as a cause of death in Australia only since 1996, and this would lead to an underestimation of HIV deaths in our cohort. In addition, ICD-10 replaced ICD-9 for the coding of deaths from 1999 onwards. However, an analysis of time trends in causes of death published by the Australian Bureau of Statistics suggests that the introduction of ICD-10 had little impact on rates. ${ }^{27}$ Furthermore, changes to some ICD codes would not affect our findings that psychiatric patients in general, and in each psychiatric diagnostic group, experienced a large gap in mortality, and that the majority of excess mortality was attributable to physical health conditions, including cancer and cardiovascular disease.

\section{Conclusions}

In summary, these results show the substantial impact of mental illness on life expectancy in Western Australia. Mental illness is common and associated with large increased risks of morbidity and mortality. While strategies aimed at the prevention of suicides and violent deaths remain an important component of efforts to reduce excess mortality in people with mental illness, our results show that almost $80 \%$ of excess deaths are associated with physical health conditions. The most common causes of death in the general population-heart disease, respiratory disease, and cancer-are also the most common causes of excess deaths in people with mental illness. Because of the complex, multifactorial nature of these conditions, multipronged approaches will be required to tackle these inequalities, in the same way that multipronged approaches have been used to reduce the mortality associated with these common conditions in the general population. These strategies should include both individual and population based components. It is more challenging treating people with multiple concurrent problems, but it is likely that treating both physical health problems and associated risk factors in people with mental illness would result in improvements to both physical and mental health.

Contributors: DL carried out the analysis and prepared the first draft, which was revised according to comments and suggestions from $\mathrm{KJH}$ and SK. DL is guarantor for the paper.

Funding: This study was supported by a grant from the Griffith Institute for Health and Medical Research. The funding source had no role in the design and conduct of the study; in the collection, analysis, and interpretation of the data; or in the preparation, review, or approval of the manuscript.

Competing interests: All authors have completed the ICMJE uniform disclosure form at www.icmje.org/coi_disclosure.pdf (available on request from the corresponding author) and declare: SK had financial support from the Griffith Institute for Health and Medical Research for the submitted work; no financial relationships with any organisations that might have an interest in the submitted work in the previous three years; no other relationships or activities that could appear to have influenced the submitted work.

Ethical approval: This study was approved by the Human Research Ethics Committee, Department of Health, Government of Western Australia.

Data sharing: No additional data available. Access to these and other data from the Western Australia Data Linkage System can be sought through www.datalinkage-wa.org/.

1 Harris EC, Barraclough B. Excess mortality of mental disorder. Br J Psychiatry 1998;173:11-53.

2 Lawrence D, Kisely S, Pais J. The epidemiology of excess mortality in people with mental illness. Can J Psychiatry 2010;55:752-60.

3 Harris EC, Barraclough B. Suicide as an outcome for mental disorders. A meta-analysis. Br J Psychiatry 1997;170:205-28.

4 De Hert M, Correll CU, Bobes J, Cetkovich-Bakmas M, Cohen D, Asai I, et al. Physical illness in patients with severe mental disorders. I. prevalence, impact of medications and disparities in health care. World Psychiatry 2011;10:52-77.

5 Lawrence D, Holman CDJ, Jablensky AV. Duty to care: preventable physical illness in people with mental illness. University of Western Australia, 2001.

6 Leucht S, Burkhard T, Henderson J, Maj M, Sartorius N. Physical illness and schizophrenia: a review of the evidence. Cambridge University Press, 2007.

7 Piatt EE, Munetz MR, Ritter C. An examination of premature mortality among decedents with serious mental illness and those in the general population. Psychiatr Serv 2010;61:663-8. 


\section{What is already known on this topic}

People with mental illness have a shorter life expectancy than the general population

\section{What this study adds}

The gap in life expectancy between people with mental illness and the general population of Western Australia increased between 1985 and 2005, particularly for people with stress or adjustment disorder, affective psychoses, and other psychoses

Significant gaps in life expectancy remained for other psychiatric disorders

The majority of excess mortality in people with mental illness was attributed to common physical health conditions such as cardiovascular disease, respiratory disease, and cancer

8 Lawrence D, Jablensky AV, Holman CDJ, Pinder TJ. Mortality in Western Australian psychiatric patients. Soc Psychiatry Psychiatr Epidemiol 2000;35:341-7.

9 Dembling BP, Chen DT, Vachon L. Life expectancy and causes of death in a population treated for serious mental illness. Psychiatr Serv 1999;50:1036-42.

10 Hannerz $\mathrm{H}$, Borgå P, Borritz M. Life expectancies for individuals with psychiatric diagnoses. Public Health 2001;115:328-37.

11 Laursen TM. Life expectancy among persons with schizophrenia or bipolar affective disorder. Schizophr Res 2011;131:101-4

12 Wahlbeck K, Westman J, Nordentoft M, Gissler M, Laursen TM. Outcomes of Nordic mental health systems: life expectancy of patients with mental disorders. Br J Psychiatry 2011;199:453-8.

13 Chang CK, Hayes RD, Perera G, Broadbent MT, Fernandes AC, Lee WE, et al. Life expectancy at birth for people with serious mental illness and other major disorders from a secondary mental health care case register in London. PLOS One 2011;6:e19590.

14 Osby U, Correia N, Brandt L, Ekbom A, Sparén P. Time trends in schizophrenia mortality in Stockholm County, Sweden: cohort study. BMJ 2000;321:483-4.

15 Saha S, Chant D, McGrath J. A systematic review of mortality in schizophrenia: is the differential mortality gap worsening over time? Arch Gen Psychiatry 2007:64:1123-31.

16 Thornicroft $G$. Physical health disparities and mental illness: the scandal of premature mortality. Br J Psychiatry 2011;199:441-2.

17 Australian Bureau of Statistics. Population by age and sex, Australian states and territories, June 2010. Cat. 3201.0. Australian Bureau of Statistics, 2010

18 Morgan VA, Jablensky AV. From inventory to benchmark: quality of psychiatric case registers in research. Br J Psychiatry 2010;197:8-10.

19 Jablensky AV, Morgan V, Zubrick SR, Bower C, Yellachich L. Pregnancy, delivery, and neonatal complications in a population cohort of women with schizophrenia and major affective disorders. Am J Psychiatry 2005;162:79-91.

20 World Health Organization. Manual of the international statistical classification of diseases, injuries, and causes of death, 9th revision. WHO, 1977.

21 World Health Organization. The international statistical classification of diseases and related health problems, 10th revision (ICD-10). WHO, 1992.

22 Holman CDJ, Bass AJ, Rouse IL, Hobbs MST. Population-based linkage of health records in Western Australia: development of a health services research linked database. Aust N Z J Public Health 1999;23:453-9.

23 World Health Organization. Manual of the international statistical classification of diseases, injuries, and causes of death, 8th revision. WHO, 1965.

24 National Coding Centre. The Official NCC Australian version of the international classification of diseases, 9th revision, clinical modification (ICD-9-CM). NCC, 1996.

25 National Casemix and Classification Centre. International statistical classification of diseases and related health problems, 10th revision, Australian modification (ICD-10-AM). National Casemix and Classification Centre, 2010.

26 Anderson RN, Miniño AM, Hoyert DL, Rosenberg HM. Comparability of cause of death between ICD-9 and ICD-10: preliminary estimates. Nat Vital Stat Rep 2001:49:1-32.

27 Australian Bureau of Statistics. Causes of death, Australia, 2008. Cat. No 3303.0. ABS, 2010.

28 Australian Bureau of Statistics. Suicides, Australia, 2010. Cat. No 3309.0. ABS, 2012

29 Chiang CL. The life table and its applications. Krieger, 1984.

30 Methodology group at the Office for National Statistics. Life expectancy at birth: methodological options for small populations. National statistics methodological series. Office for National Statistics, 2003.

31 Silcocks PBS, Jenner DA, Reza R. Life expectancy as a summary of mortality in a population: statistical considerations and suitability for use by health authorities. J Epidemiol Community Health 2001;55:38-43.

32 Australian Bureau of Statistics. Life tables, Western Australia, 2008-2010, Cat. No 3302.5.55.001. ABS, 2011

33 Australian Bureau of Statistics. Causes of death, Australia, 2009, Cat. № 3303.0. ABS, 2011.

34 SAS Institute. SAS 9.2 Help and documentation. SAS Institute, 2002-09.

35 United Nations Population Division. World population prospects, the 2010 revision. http /esa.un.org/wpp/unpp/panel population.htm.

36 Doll R, Peto R, Boreham J, Sutherland I. Mortality in relation to smoking: 50 years observations on male British doctors. BMJ 2004;328:1519.

37 Australian Bureau of Statistics. Experimental life tables for Aboriginal and Torres Strait Islander Australians, 2005-2007, Cat. No 3302.0.55.003. ABS, 2009.

38 Council of Australian Governments. National indigenous reform agreement (closing the ap). Council of Australian Governments, 2008.
39 Australian Government Department of Health and Ageing Living is for everyone: a framework for prevention of suicide in Australia. Australian Government Department of Health and Ageing, 2008.

40 Lawrence DM, Holman CDJ, Jablensky AV, Hobbs MST. Death rate from ischaemic heart disease in Western Australian psychiatric patients 1980-1998. Br J Psychiatry 2003;182:31-3.

41 Lambert TJR, Velakoulis D, Pantelis C. Medical comorbidity in schizophrenia. Med J Aust 2003;178:S67.

42 De Leon J, Diaz FJ. A meta-analysis of worldwide studies demonstrates an association between schizophrenia and tobacco smoking behaviors. Schizophr Res 2005;76:135-57.

43 Lawrence D, Mitrou F, Zubrick SR. Smoking and mental illness: results from population surveys in Australia and the United States. BMC Public Health 2009:9:285.

44 Australian Bureau of Statistics. National survey of mental health and wellbeing: summary of results, 2007, Cat. No 4326.0. ABS, 2008.

45 Osborn DPJ, Nazareth I, King MB. Physical activity, dietary habits and coronary heart disease risk factor knowledge amongst people with severe mental illness: a cross sectiona comparative study in primary care. Soc Psychiatry Psychiatr Epidemiol 2007:42:787-93.

46 Kendrick T. Cardiovascular and respiratory risk factors and symptoms among general practice patients with long-term mental illness. Br J Psychiatry 1996;169:733-9.

47 Davidson S, Judd F, Jolley D, Hocking B, Thompson S, Hyland B. Cardiovascular risk factors for people with mental illness. Aust N Z J Psychiatry 2001;35:196-202.

48 Smoller JW, Allison M, Cochrane BB, Curb JD, Perlis RH, Robinson JG, et al. Antidepressant use and risk of incident cardiovascular morbidity and mortality among postmenopausal women in the Women's Health Initiative study. Arch Intern Med 2009;169:2128-39.

49 Ray WA, Chung CP, Murray KT, Hall K, Stein CM. Atypical antipsychotic drugs and the risk of sudden cardiac death. N Engl J Med 2009;360:225-35.

50 Lawrence D, Kisely S. Inequalities in healthcare provision for people with severe mental illness. J Psychopharmacol 2010;24:61-8.

51 Muntaner C, Eaton WW, Miech R, O'Campo P. Socioeconomic position and major mental disorders. Epidemiol Rev 2004;26:53-62.

52 Druss BG, Rorhbaugh RM, Levinson CM, Rosenheck RA. Integrated medical care for patients with serious psychiatric illness: a randomized trial. Arch Gen Psychiatry 2001;58:861-8.

53 Carney CP, Jones LE. The influence of type and severity of mental illness on receipt of screening mammography. J Gen Intern Med 2006:21:1097-104.

54 Pirkis J, Harris M, Hall W, Ftanou M. Evaluation of the better access to psychiatrists, psychologists and general practitioners through the Medicare Benefits Schedule Initiative. Summative evaluation. Centre for Health Policy, Programs and Economics. University of Melbourne, 2011

55 Bates AJ, Kemp V, Isaac MK. Peer support shows promise in helping persons living with mental illness address their physical health needs. Can J Community Mental Health 2008;27:21-36.

56 Druss BG, Zhao L, von Esenwein SA, Bona JR, Fricks L, Jenkins-Tucker S, et al. The health and recovery peer (HARP) program: a peer-led intervention to improve medical self-management for persons with serious mental illness. Schizophr Res 2010;118:264-70.

57 Royal College of Psychiatrists. Whole-person care: from rhetoric to reality. Achieving parity between mental and physical health. Occasional paper OP88. Royal College of Psychiatrists, 2013.

58 General Practice Queensland. Activate: mind and body. 2013. www.activatemindandbody. com.au/.

59 Lawrence D, Lawn S, Kisely S, Bates A, Mitrou F, Zubrick SR. The potential impact of smoke-free facilities on smoking cessation in people with mental illness. Aust $N Z J$ Psychiatry 2011;45:1053-60.

60 Corrigan PW, ed. On the stigma of mental illness: practical strategies for research and social change. American Psychological Association, 2005.

\section{Accepted: 15 April 2013}

\section{Cite this as: BMJ 2013;346:f2539}

This is an Open Access article distributed in accordance with the Creative Commons Attribution Non Commercial (CC BY-NC 3.0) license, which permits others to distribute, remix, adapt, build upon this work non-commercially, and license their derivative works on different terms, provided the original work is properly cited and the use is non-commercial. See: http://creativecommons.org/licenses/by-nc/3.0/. 


\section{Tables}

Table 1| Numbers of active cases and deaths in first and last cohorts included in study

\begin{tabular}{|c|c|c|c|c|c|c|c|c|}
\hline \multirow[b]{3}{*}{ Primary diagnoses } & \multicolumn{4}{|c|}{ Males } & \multicolumn{4}{|c|}{ Females } \\
\hline & \multicolumn{2}{|c|}{ 1983-87 } & \multicolumn{2}{|c|}{ 2003-07 } & \multicolumn{2}{|c|}{ 1983-87 } & \multicolumn{2}{|c|}{ 2003-07 } \\
\hline & Active cases & Deaths & Active cases & Deaths & Active cases & Deaths & Active cases & Deaths \\
\hline Alcohol or drug disorders & 5198 & 438 & 8163 & 764 & 1665 & 95 & 4191 & 209 \\
\hline Schizophrenia & 3440 & 228 & 8073 & 399 & 2733 & 182 & 5027 & 286 \\
\hline Affective psychosis & 2995 & 130 & 8798 & 537 & 5402 & 160 & 14537 & 660 \\
\hline Other psychoses & 1973 & 178 & 2753 & 531 & 1823 & 182 & 1941 & 456 \\
\hline Neurotic disorders & 2732 & 97 & 4988 & 372 & 5153 & 129 & 8633 & 561 \\
\hline Stress or adjustment reaction & 3918 & 67 & 9563 & 381 & 6032 & 44 & 13673 & 312 \\
\hline Depressive disorder & 3501 & 193 & 7630 & 719 & 6891 & 213 & 13813 & 750 \\
\hline Other mental disorder & 5312 & 79 & 17888 & 444 & 3824 & 56 & 19743 & 310 \\
\hline Total & 29069 & 1410 & 67856 & 4147 & 33523 & 1061 & 81558 & 3544 \\
\hline
\end{tabular}


Table 2/ Life expectancy and difference in life expectancy for people in recent contact with mental health services in Western Australia 1985,1995 , and 2005, by primary psychiatric diagnosis and sex

\begin{tabular}{|c|c|c|c|}
\hline \multirow[b]{2}{*}{ Primary diagnoses } & \multicolumn{3}{|c|}{ Years $(95 \% \mathrm{Cl})$} \\
\hline & 1985 & 1995 & 2005 \\
\hline \multicolumn{4}{|l|}{ Males } \\
\hline Western Australian population & 73.1 & 75.4 & 79.1 \\
\hline \multicolumn{4}{|l|}{ Alcohol or drug disorders: } \\
\hline Life expectancy & $52.7(51.1$ to 54.4$)$ & 52.5 (50.8 to 54.2$)$ & 57.4 (56.0 to 58.9$)$ \\
\hline Difference & 20.4 (18.7 to 22.1$)$ & 22.9 (21.2 to 24.6$)$ & 21.6 (20.1 to 23.1$)$ \\
\hline \multicolumn{4}{|l|}{ Schizophrenia: } \\
\hline Life expectancy & 58.6 (56.5 to 60.7$)$ & $60.0(58.5$ to 61.5$)$ & 62.7 (61.1 to 64.3$)$ \\
\hline Difference & 14.5 (12.4 to 16.6$)$ & $15.4(13.9$ to 16.9$)$ & $16.4(14.7$ to 18.0$)$ \\
\hline \multicolumn{4}{|l|}{ Affective psychosis: } \\
\hline Life expectancy & 64.0 (61.7 to 66.3$)$ & 65.1 (63.3 to 66.8$)$ & 64.9 (62.9 to 67.0$)$ \\
\hline Difference & $9.1(6.7$ to 11.4$)$ & $10.3(8.6$ to 12.1$)$ & $14.1(12.1$ to 16.2$)$ \\
\hline \multicolumn{4}{|l|}{ Other psychoses: } \\
\hline Life expectancy & 58.3 (54.5 to 62.0$)$ & 53.4 (50.5 to 56.4$)$ & 56.3 (54.2 to 58.5$)$ \\
\hline Difference & 14.8 (11.0 to 18.6$)$ & $22.0(19.1$ to 25.0$)$ & 22.7 (20.5 to 24.9 ) \\
\hline \multicolumn{4}{|l|}{ Neurotic disorders: } \\
\hline Life expectancy & 63.5 (61.2 to 65.8$)$ & 68.1 (66.0 to 70.3 ) & 66.7 (64.7 to 68.8$)$ \\
\hline Difference & 9.6 (7.3 to 11.9$)$ & $7.3(5.1$ to 9.4$)$ & $12.3(10.3$ to 14.4$)$ \\
\hline \multicolumn{4}{|l|}{ Stress or adjustment reaction: } \\
\hline Life expectancy & 65.8 (62.5 to 69.1$)$ & 65.9 (63.9 to 68.0$)$ & $65.9(64.1$ to 67.7$)$ \\
\hline Difference & $7.3(4.0$ to 10.6$)$ & 9.5 (7.4 to 11.6$)$ & $13.2(11.3$ to 15.0$)$ \\
\hline \multicolumn{4}{|l|}{ Depressive disorder: } \\
\hline Life expectancy & 60.7 (58.7 to 62.8$)$ & $62.0(60.0$ to 64.0$)$ & 63.8 (62.3 to 65.3$)$ \\
\hline Difference & $12.4(10.3$ to 14.4$)$ & $13.4(11.4$ to 15.5$)$ & $15.3(13.8$ to 16.8$)$ \\
\hline \multicolumn{4}{|l|}{ Other mental disorder: } \\
\hline Life expectancy & 62.5 (59.8 to 65.2$)$ & $68.8(65.2$ to 72.4$)$ & 65.7 (64.1 to 67.2$)$ \\
\hline Difference & 10.6 (7.9 to 13.3$)$ & 6.6 (3.0 to 10.2$)$ & 13.4 (11.9 to 15.0$)$ \\
\hline \multicolumn{4}{|l|}{ All mental disorders: } \\
\hline Life expectancy & 59.6 (58.8 to 60.3$)$ & $60.8(60.2$ to 61.5$)$ & 63.2 (62.6 to 63.7$)$ \\
\hline Difference & $13.5(12.7$ to 14.3$)$ & 14.6 (13.9 to 15.3$)$ & 15.9 (15.3 to 16.5$)$ \\
\hline \multicolumn{4}{|l|}{ Females } \\
\hline Western Australian population & 79.3 & 81.4 & 83.8 \\
\hline \multicolumn{4}{|l|}{ Alcohol or drug disorders: } \\
\hline Life expectancy & 55.4 (52.0 to 58.8$)$ & 57.3 (54.9 to 59.7$)$ & 63.1 (60.1 to 66.1$)$ \\
\hline Difference & 23.9 (20.5 to 27.3$)$ & 24.1 (21.6 to 26.5$)$ & 20.7 (17.7 to 23.7$)$ \\
\hline \multicolumn{4}{|l|}{ Schizophrenia: } \\
\hline Life expectancy & 66.5 (64.2 to 68.7$)$ & 69.5 (67.9 to 71.1$)$ & 71.3 (69.3 to 73.3$)$ \\
\hline Difference & $12.9(10.6$ to 15.2$)$ & $11.8(10.2$ to 13.5$)$ & $12.5(10.5$ to 14.5$)$ \\
\hline \multicolumn{4}{|l|}{ Affective psychosis: } \\
\hline Life expectancy & 72.1 (70.2 to 74.0$)$ & 73.3 (72.0 to 74.6$)$ & 73.9 (72.5 to 75.3$)$ \\
\hline Difference & 7.2 (5.3 to 9.1$)$ & $8.0(6.7$ to 9.3$)$ & 9.9 (8.4 to 11.3$)$ \\
\hline \multicolumn{4}{|l|}{ Other psychoses: } \\
\hline Life expectancy & $65.2(61.9$ to 68.6$)$ & 58.9 (53.0 to 64.9$)$ & $61.2(57.6$ to 64.8$)$ \\
\hline Difference & $14.1(10.7$ to 17.5$)$ & $22.4(16.5$ to 28.4$)$ & 22.6 (19.0 to 26.2$)$ \\
\hline \multicolumn{4}{|l|}{ Neurotic disorders: } \\
\hline Life expectancy & $71.0(69.0$ to 73.1$)$ & 76.7 (75.0 to 78.5$)$ & 74.1 (72.4 to 75.7$)$ \\
\hline Difference & 8.3 (6.3 to 10.3$)$ & $4.6(2.9$ to 6.4$)$ & $9.7(8.0$ to 11.4$)$ \\
\hline
\end{tabular}


Table 2 (continued)

\begin{tabular}{|c|c|c|c|}
\hline \multirow[b]{2}{*}{ Primary diagnoses } & \multicolumn{3}{|c|}{ Years $(95 \% \mathrm{Cl})$} \\
\hline & 1985 & 1995 & 2005 \\
\hline \multicolumn{4}{|c|}{ Stress or adjustment reaction: } \\
\hline Life expectancy & 79.5 (72.4 to 86.6$)$ & 80.4 (77.2 to 83.6$)$ & 74.5 (72.5 to 76.4$)$ \\
\hline Difference & $-0.2(-7.3$ to 6.9$)$ & $0.9(-2.3$ to 4.1$)$ & 9.3 (7.3 to 11.3$)$ \\
\hline \multicolumn{4}{|l|}{ Depressive disorder: } \\
\hline Life expectancy & $69.1(67.4$ to 70.9$)$ & 72.7 (71.0 to 74.4$)$ & 71.3 (69.6 to 72.9$)$ \\
\hline Difference & 10.2 (8.4 to 12.0$)$ & $8.6(6.9$ to 10.4$)$ & 12.5 (10.8 to 14.2$)$ \\
\hline \multicolumn{4}{|l|}{ Other mental disorder: } \\
\hline Life expectancy & 67.7 (63.6 to 71.9 ) & 70.1 (66.9 to 73.3 ) & 71.7 (70.0 to 73.5$)$ \\
\hline Difference & 11.6 (7.4 to 15.8$)$ & $11.2(8.0$ to 14.4$)$ & 12.1 (10.3 to 13.8 ) \\
\hline \multicolumn{4}{|l|}{ All mental disorders: } \\
\hline Life expectancy & 68.9 (68.1 to 69.6$)$ & 70.9 (70.3 to 71.5$)$ & 71.8 (71.2 to 72.4$)$ \\
\hline Difference & 10.4 (9.6 to 11.2 ) & 10.5 (9.8 to 11.1$)$ & 12.0 (11.3 to 12.6 ) \\
\hline
\end{tabular}




\begin{tabular}{|c|c|c|c|c|c|c|c|c|c|}
\hline \multirow[b]{2}{*}{ Causes of death } & \multicolumn{9}{|c|}{ Primary psychiatric diagnoses } \\
\hline & $\begin{array}{c}\text { All } \\
\text { disorders }\end{array}$ & $\begin{array}{l}\text { Alcohol or } \\
\text { drug } \\
\text { disorders }\end{array}$ & Schizophrenia & $\begin{array}{l}\text { Affective } \\
\text { psychosis }\end{array}$ & $\begin{array}{c}\text { Other } \\
\text { psychoses }\end{array}$ & $\begin{array}{l}\text { Neurotic } \\
\text { disorders }\end{array}$ & $\begin{array}{l}\text { Stress or } \\
\text { adjustment } \\
\text { reaction }\end{array}$ & $\begin{array}{l}\text { Depressive } \\
\text { disorder }\end{array}$ & $\begin{array}{c}\text { Other } \\
\text { mental } \\
\text { disorder }\end{array}$ \\
\hline \multicolumn{10}{|l|}{ Males } \\
\hline Total No of deaths & 8064 & 2142 & 1218 & 795 & 1457 & 511 & 487 & 1027 & 427 \\
\hline Expected No of deaths & 3133 & 526 & 398 & 419 & 479 & 287 & 289 & 470 & 265 \\
\hline \multicolumn{10}{|l|}{$\begin{array}{l}\text { Distribution of excess deaths } \\
\text { by cause: }\end{array}$} \\
\hline Ischaemic heart disease & 14.4 & 13.7 & 16.2 & 16.0 & 13.4 & 24.7 & 4.2 & 15.8 & 6.1 \\
\hline Cerebrovascular disease & 5.7 & 4.8 & 6.5 & 2.2 & 11.0 & 6.8 & 0.0 & 2.4 & 2.5 \\
\hline Other heart disease & 6.1 & 4.8 & 9.1 & 3.0 & 8.1 & 6.8 & 4.6 & 5.1 & 3.6 \\
\hline Malignant neoplasms & 13.6 & 17.0 & 8.9 & 1.7 & 17.9 & 12.9 & 14.0 & 15.9 & 0.0 \\
\hline $\begin{array}{l}\text { Chronic obstructive } \\
\text { pulmonary disease }\end{array}$ & 6.4 & 6.7 & 5.8 & 5.8 & 5.4 & 8.5 & 2.2 & 9.8 & 5.0 \\
\hline Influenza and pneumonia & 3.6 & 4.5 & 4.3 & 3.3 & 5.0 & 1.0 & 0.0 & 0.6 & 2.4 \\
\hline Diabetes mellitus & 1.9 & 0.7 & 3.3 & 3.2 & 2.7 & 1.5 & 0.0 & 1.1 & 4.1 \\
\hline HIV & 0.3 & 0.1 & 0.3 & 0.2 & 0.4 & 0.0 & 1.3 & 0.7 & 1.0 \\
\hline $\begin{array}{l}\text { Chronic liver disease or } \\
\text { cirrhosis }\end{array}$ & 5.3 & 12.2 & 1.1 & 0.0 & 3.3 & 2.5 & 0.5 & 3.3 & 0.2 \\
\hline Kidney disease & 0.9 & 0.6 & 1.3 & 0.3 & 1.5 & 0.8 & 0.0 & 0.5 & 0.7 \\
\hline Dementia & 0.5 & 0.1 & 1.2 & 0.3 & 1.6 & 0.0 & 0.0 & 0.0 & 0.3 \\
\hline Alzheimer's disease & 0.4 & 0.0 & 1.9 & 0.0 & 1.1 & 0.0 & 0.0 & 0.0 & 0.0 \\
\hline Other & 15.3 & 18.2 & 11.8 & 10.2 & 17.4 & 11.0 & 8.9 & 14.1 & 19.1 \\
\hline Suicide & 16.6 & 6.1 & 19.8 & 46.4 & 5.3 & 16.2 & 53.3 & 22.7 & 33.4 \\
\hline Homicide & 0.6 & 1.4 & 0.4 & 0.4 & 0.2 & 0.0 & 0.1 & 0.3 & 0.0 \\
\hline $\begin{array}{l}\text { Complications of medical or } \\
\text { surgical care }\end{array}$ & 0.2 & 0.1 & 0.5 & 0.5 & 0.1 & 0.4 & 0.4 & 0.1 & 0.0 \\
\hline Other accident or injury & 8.1 & 9.0 & 7.5 & 6.5 & 5.4 & 6.9 & 10.6 & 7.7 & 21.5 \\
\hline \multicolumn{10}{|l|}{ Females } \\
\hline Total No of deaths & 6553 & 579 & 1066 & 988 & 1399 & 682 & 378 & 1177 & 284 \\
\hline Expected No of deaths & 3125 & 103 & 399 & 546 & 561 & 479 & 283 & 619 & 135 \\
\hline
\end{tabular}

Distribution of excess deaths

by cause:

\begin{tabular}{|c|c|c|c|c|c|c|c|c|c|}
\hline Ischaemic heart disease & 16.9 & 11.5 & 18.2 & 14.4 & 17.0 & 25.1 & 0.0 & 23.2 & 8.6 \\
\hline Cerebrovascular disease & 11.3 & 7.4 & 18.3 & 7.3 & 16.6 & 8.1 & 0.0 & 6.4 & 5.3 \\
\hline Other heart disease & 7.1 & 7.9 & 9.8 & 4.6 & 7.0 & 4.4 & 0.6 & 7.8 & 3.9 \\
\hline Malignant neoplasms & 13.3 & 16.4 & 7.1 & 5.2 & 16.9 & 17.3 & 20.9 & 15.9 & 10.4 \\
\hline $\begin{array}{l}\text { Chronic obstructive } \\
\text { pulmonary disease }\end{array}$ & 6.5 & 5.9 & 5.6 & 9.1 & 5.7 & 12.7 & 0.9 & 7.0 & 2.0 \\
\hline Influenza and pneumonia & 2.5 & 3.2 & 3.0 & 2.6 & 3.7 & 0.0 & 0.0 & 1.8 & 2.1 \\
\hline Diabetes mellitus & 2.7 & 3.1 & 4.0 & 1.8 & 2.9 & 0.4 & 2.2 & 2.2 & 2.4 \\
\hline HIV & 0.0 & 0.0 & 0.0 & 0.0 & 0.0 & 0.0 & 0.0 & 0.0 & 0.0 \\
\hline $\begin{array}{l}\text { Chronic liver disease or } \\
\text { cirrhosis }\end{array}$ & 3.2 & 13.2 & 0.8 & 0.0 & 1.5 & 2.6 & 7.7 & 1.6 & 4.4 \\
\hline Kidney disease & 1.8 & 1.6 & 2.2 & 1.4 & 2.6 & 0.9 & 0.0 & 2.1 & 0.0 \\
\hline Dementia & 1.0 & 0.4 & 3.5 & 0.2 & 2.0 & 0.0 & 0.0 & 0.0 & 0.9 \\
\hline Alzheimer's disease & 0.7 & 0.0 & 3.3 & 0.2 & 1.1 & 0.0 & 0.0 & 0.0 & 0.5 \\
\hline Other & 15.1 & 18.4 & 11.0 & 15.8 & 15.7 & 11.9 & 16.2 & 11.3 & 32.6 \\
\hline Suicide & 10.1 & 2.1 & 7.1 & 27.4 & 2.9 & 8.3 & 33.5 & 11.8 & 14.8 \\
\hline Homicide & 0.4 & 1.4 & 0.2 & 0.1 & 0.0 & 0.7 & 4.4 & 0.1 & 0.4 \\
\hline $\begin{array}{l}\text { Complications of medical or } \\
\text { surgical care }\end{array}$ & 0.3 & 0.4 & 0.1 & 0.3 & 0.2 & 0.2 & 0.0 & 0.4 & 0.5 \\
\hline
\end{tabular}


Table 3 (continued)

\begin{tabular}{|c|c|c|c|c|c|c|c|c|c|}
\hline \multirow[b]{2}{*}{ Causes of death } & \multicolumn{9}{|c|}{ Primary psychiatric diagnoses } \\
\hline & $\begin{array}{c}\text { All } \\
\text { disorders }\end{array}$ & $\begin{array}{c}\text { Alcohol or } \\
\text { drug } \\
\text { disorders }\end{array}$ & Schizophrenia & $\begin{array}{l}\text { Affective } \\
\text { psychosis }\end{array}$ & $\begin{array}{c}\text { Other } \\
\text { psychoses }\end{array}$ & $\begin{array}{l}\text { Neurotic } \\
\text { disorders }\end{array}$ & $\begin{array}{l}\text { Stress or } \\
\text { adjustment } \\
\text { reaction }\end{array}$ & $\begin{array}{c}\text { Depressive } \\
\text { disorder }\end{array}$ & $\begin{array}{c}\text { Other } \\
\text { mental } \\
\text { disorder }\end{array}$ \\
\hline Other accident or injury & 7.0 & 7.1 & 5.7 & 9.5 & 4.0 & 7.2 & 13.6 & 8.2 & 11.1 \\
\hline
\end{tabular}




\section{Figures}
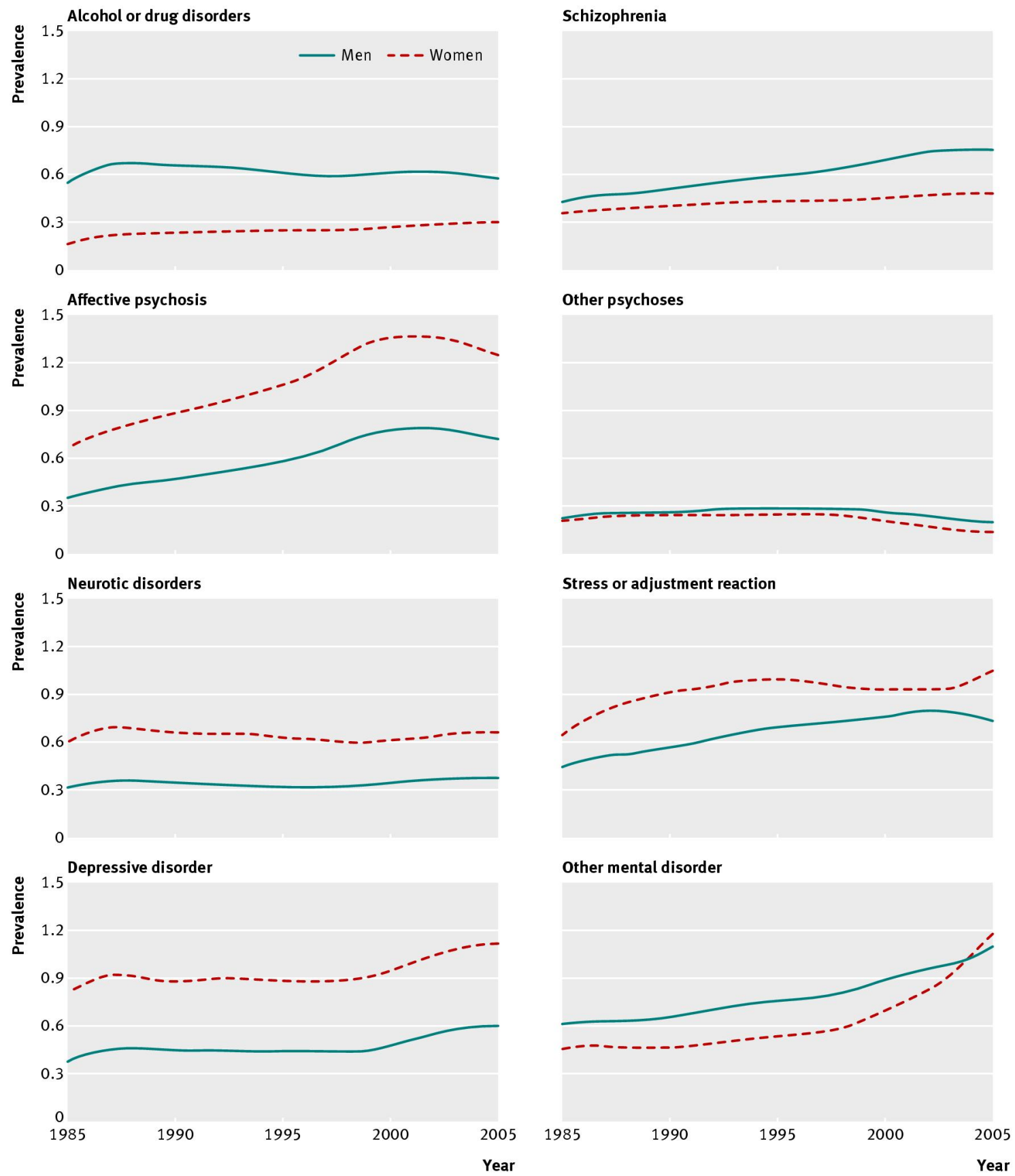

Fig 1 Active (five year) prevalence of mental disorders in people aged 15 and over, as assessed by contact with mental health services in past five years in Western Australia, by year and sex 
— People with mental illness $\quad 95 \% \mathrm{Cl} \quad---$ Western Australia population
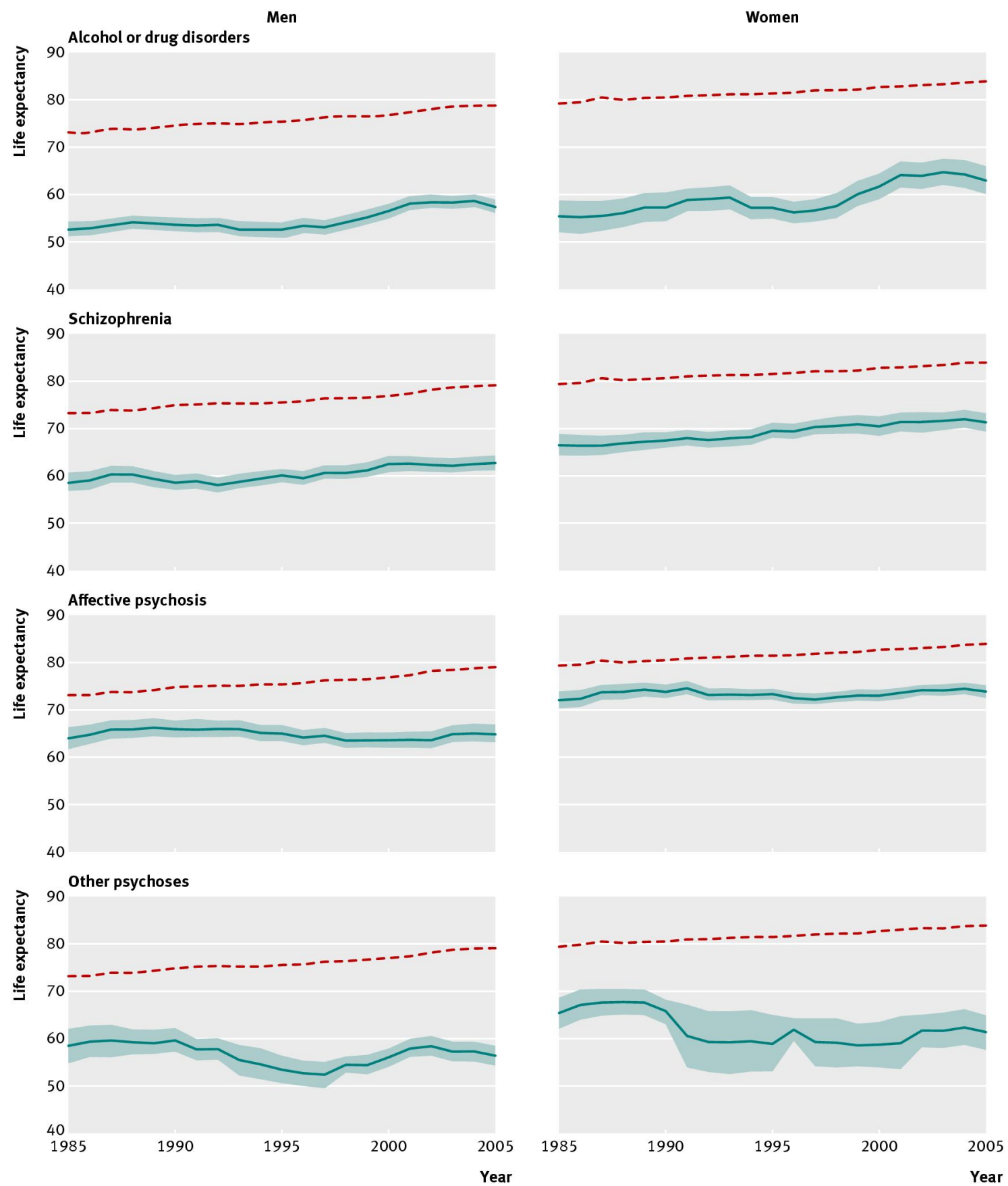

Fig 2 Life expectancy of people with alcohol or drug disorders, schizophrenia, and affective or other psychoses compared with the Western Australia population, by year and sex 
— People with mental illness $\quad 95 \% \mathrm{Cl} \quad---$ Western Australia population
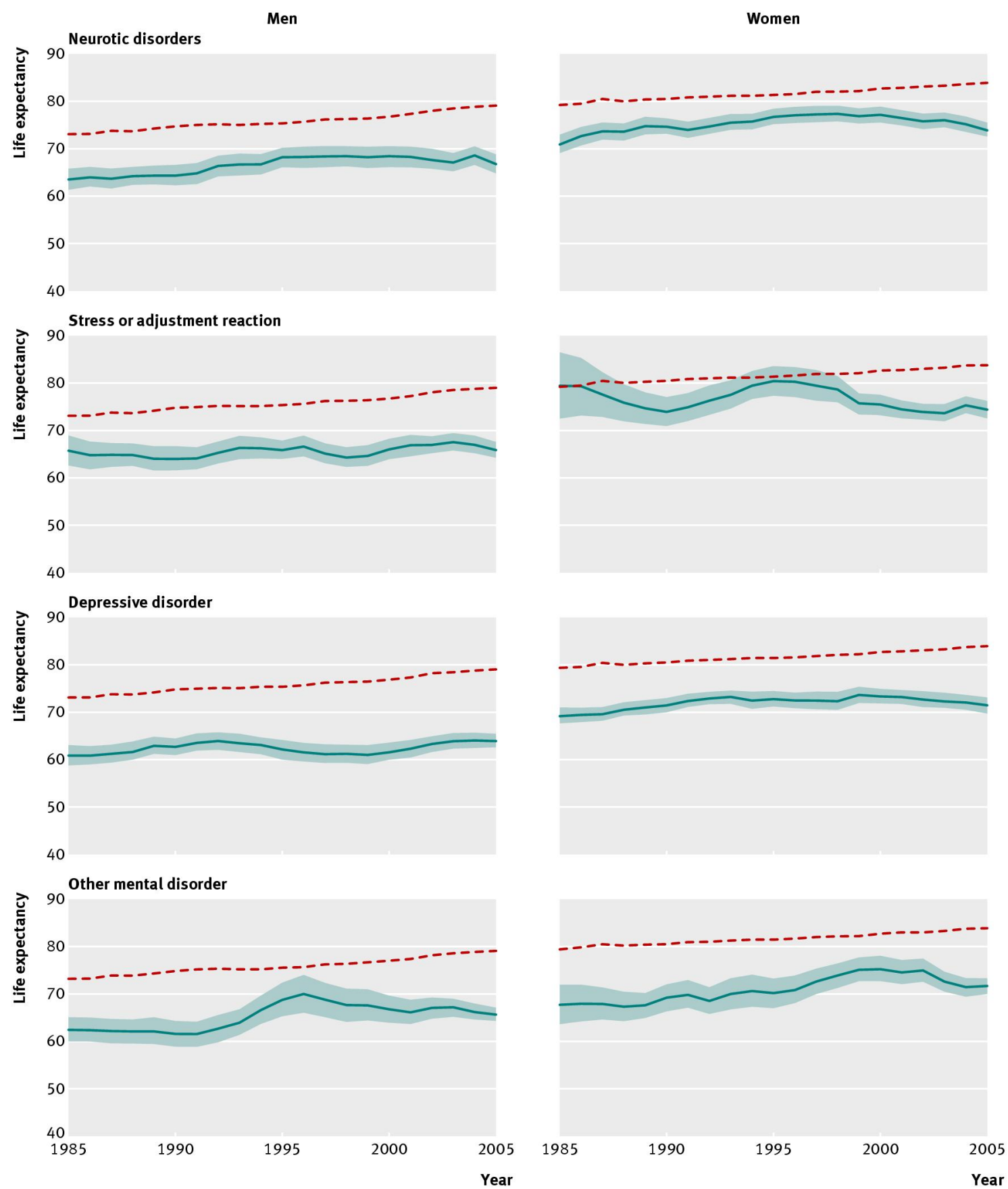

Fig 3 Life expectancy of people with selected non-psychotic mental disorders compared with the Western Australia population, by year and sex 